\title{
MORTALIDAD INFANTIL POR DESNUTRICIÓN Y CONDICIONES DE POBREZA EN TUCUMÁN (ARGENTINA): MAGNITUDES, MANIFESTACIONES ESPACIALES Y ACCIONES FAMILIARES EN LOS PRIMEROS AÑOS DEL SIGLO XXI
}

\author{
Fernando Longhi ${ }^{1} \&$ Alejandra del Castillo ${ }^{2}$ \\ Universidad Nacional de Tucumán
}

\begin{abstract}
RESUMEN
El problema de la desnutrición infantil en Tucumán adquirió una repercusión inusitada en los inicios del siglo XXI. Pudo observarse que, lejos de estar solucionado, adquiría, en los albores del siglo XXI, magnitudes increíbles para Argentina en general y para Tucumán en particular. Sin embargo, más allá de lo "novedoso" del problema y la "sorpresa" por su magnitud, muchas características elementales del problema se ignoraban. En esta propuesta pretendimos aproximarnos al complejo mundo de la desnutrición infantil en Tucumán durante los primeros años del siglo XXI, detectando las principales manifestaciones que adquiría el problema extremo de la mortalidad en la niñez por desnutrición, tanto en sus tendencias temporales como en sus expresiones espaciales. Se buscó también, a través de estudios de caso, examinar las relaciones entre el contexto de pobreza, la morbilidad de la desnutrición infantil y las acciones familiares desplegadas. Los resultados advierten que, si bien las magnitudes descendieron, los casos de muerte aun son numerosos, más aún los de morbilidad (en cuyos casos las secuelas generan un daño irreversible), además su presencia se relaciona con contextos de pobreza persistente, y las acciones familiares desplegadas solo tendieron a la atenuación en la gravedad del problema.

Palabras clave: desnutrición infantil; pobreza; Tucumán; Siglo XXI; mortalidad infantil.

\section{MORTALITY OF CHILDREN FOR UNDERNUTRITION AND CONDITIONS OF POVERTY IN TUCUMÁN (ARGENTINA): MAGNITUDES, SPATIAL MANIFESTATIONS AND FAMILY ACTIONS IN THE FIRST YEARS OF THE 21ST CENTURY}

\section{ABSTRACT}

The problem of child malnutrition in Tucumán acquired an unprecedented impact at the beginning of the 21 st century. It could be observed that, far from being solved, it acquired, at the dawn of the century, incredible magnitudes for Argentina in general and particularly for Tucumán. However, beyond the "novel" of the problem and the "surprise" by this magnitude, many elementary features of the problem were ignored. In this proposal we intend to approach the complex world of child malnutrition in Tucumán during the first years of the 21st century, detecting the main manifestations that acquired the extreme problem of child mortality due to malnutrition, both in their temporal tendencies and in their spatial expressions. It was also sought, trough case studies, to examine the relationships between the context of poverty, the morbidity of child undernutrition, and family actions deployed. The results shows that although the magnitudes decreased, the cases of death are still numerous, even those of morbidity (in which cases the sequelae generate irreversible damage), and their presence is related to contexts of persistent poverty, and family actions deployed tended to attenuate only the seriousness of the problem.

Keywords: child malnutrition; poverty; Tucumán; 21st century; mortality of children

\footnotetext{
${ }^{1}$ Instituto Superior de Estudios Sociales (Concejo Nacional de Investigaciones Científicas y Técnicas Universidad Nacional de Tucumán). E-mail: fernandolonghi@hotmail.com

${ }^{2}$ Instituto Superior de Estudios Sociales (Concejo Nacional de Investigaciones Científicas y Técnicas Universidad Nacional de Tucumán). E-mail: delcale@ hotmail.com
}

Fecha de recepción: 07 de marzo de 2017. Fecha de aceptación: 26 de mayo de 2017. 


\section{INTRODUCCIÓN}

A fines de la primera década del siglo XXI los países de América Latina, en general, y Argentina, en particular, evidenciaron grandes avances en el mejoramiento de sus condiciones de vida -avances que se caracterizan a su vez como notorios si se toma como referencia principal la comparación con el decenio de los años '90-. Este proceso reconoce a su vez ciertas condiciones políticas y económicas que favorecieron el reposicionamiento del Estado en la programación e implementación de políticas públicas (Mercer, 2013). Sin embargo, existen ciertos aspectos que deben tenerse en cuenta para contextualizar tales mejoras: por un lado, se ha registrado en los últimos años de la década cierto estancamiento y/o retroceso en algunas de las dimensiones fundamentales del bienestar social, entre las que se encuentra la situación nutricional de los niños (FAO, 2014); y por otro, se detecta, a pesar de las mejoras, magnitudes elevadas aun de niños con problemas de carencia nutricional (Longhi, 2015).

Según estadísticas del Programa Mundial de Alimentos de Naciones Unidas, en América Latina la desnutrición afecta a casi 9 millones de niños menores de cinco años (16\%) (UNICEF, 2006). Se agrega a esta cifra 9 millones más de niños con alto riesgo de desnutrirse debido a las condiciones de pobreza en las que viven. De todos estos, una buena proporción se localizan en países como Guatemala, Bolivia y Honduras.

Este hecho alertaba sobre la desigualdad del acceso a la salud particularmente en la niñez, y de manera más general sobre la importante brecha en las condiciones de vida de su población. En este sentido, planteaban Martínez y Fernández (2006) lo interesante del caso de Argentina, que ha sufrido un fuerte fenómeno de contra-transición epidemiológica en los últimos años, con la reaparición de enfermedades controladas, tales como el cólera, dengue, malaria, tuberculosis y desnutrición ${ }^{3}$.

Contrastando estos datos con otras fuentes, en Argentina se observa que, a partir de los resultados de la Encuesta Nacional de Nutrición y Salud (ENNYS) realizada en 2004-05, existen una magnitud sorprendente de niños afectados con anemia (llamada también desnutrición oculta) lo cual alcanzaba en la provincia de Chaco, por ejemplo, el $36 \%$ de los niños de 6 a 72 meses, siendo el valor promedio nacional del 16.5\% (Durán et al., 2009). Este hecho evidencia un claro ejemplo de la "tiranía de los promedios" mencionada por Kliksberg $(2005)^{4}$.

En este contexto, los promedios de desnutrición infantil en Argentina serían relativamente bajos si se considera el marco latinoamericano. Sin embargo, ya a inicios del siglo XXI, la FAO destacaba que "si bien en Argentina la disponibilidad de alimentos es suficiente y aun excedente para cubrir las necesidades energéticas por persona y por día, parte de la población tiene un acceso insuficiente a los alimentos" (FAO, 2001: 12). Por otro lado, también UNICEF alertaba a mediados de los noventa que el censo de talla en escolares de primer grado realizado entre 1991 y 1994 presentaba un nivel de retardo de crecimiento particularmente elevado en las provincias de Salta, Jujuy, Formosa, Chaco y Misiones, cuyo panorama se asimilaba más al resto de América Latina que al propio promedio nacional. Estudios de Britos (2003) y Calvo et al., (2005) describían que la forma de desnutrición prevalente en Argentina antes de los 2000, era el déficit de talla o desnutrición crónica, siendo el norte la región más afectada. Se perfilaban entonces evidencias que mostraban un país con profundas asimetrías regionales, y se desconocía gran parte del problema de la desnutrición infantil, particularmente su magnitud, características y su distribución/concentración espacial.

\footnotetext{
${ }^{3}$ Mencionaban al respecto: "La transición epidemiológica es un proceso dinámico en que se pueden producir retrocesos de una etapa a la otra, por ejemplo, la reaparición del cólera, dengue, malaria y tuberculosis en algunos países cuando ya se consideraban que estaban superadas. Este fenómeno se denomina "contra-transición" y es lo que ha sucedido con la desnutrición que ha reaparecido y tiende a transformarse en una enfermedad endémica en muchos países" (Martínez et al., 2006: 23).

${ }^{4}$ Es necesario subrayar que en los promedios nacionales no se reflejan las grandes disparidades existentes dentro de los países. Por ejemplo, la probabilidad de que un niño latinoamericano que vive en una zona rural sufra de desnutrición global es entre 1,5 y 3,7 veces más alta que en un niño que vive en zona urbana, y al menos 4 veces mayor entre niños indígenas (UNICEF, 2006).
} 
El deterioro en los indicadores de empleo y desigualdad en la distribución de los ingresos y la expansión de la pobreza registrados durante la década de 1990, crearon las condiciones para un fuerte empeoramiento de la situación alimentaria del país. En los inicios del siglo XXI., particularmente en el año 2002, el problema de la desnutrición en la niñez argentina tomó una repercusión inusitada, concentrado -originalmente- en la provincia de Tucumán. Fueron numerosos los casos de desnutrición que salieron a la luz y que permitían un "redescubrimiento" del problema; los cuales fueron divulgados -principalmente- en notas de periódicos nacionales e internacionales, alcanzando visibilidad tanto en los ámbitos políticos, técnicos, académicos y mediáticos (Demonte, 2011). Pudo así observarse, que el problema de la desnutrición estaba lejos de ser solucionado y adquiría, a comienzos del siglo XXI, magnitudes increíbles para Argentina en general como para Tucumán en particular.

Frente a lo expuesto, en esta propuesta pretendemos aproximarnos a detectar las principales manifestaciones de la desnutrición crónica infantil en la provincia de Tucumán durante los primeros años del siglo XXI, detectando tanto sus tendencias temporales como su distribución espacial. Este objetivo está fuertemente articulado con las fortalezas y limitaciones de las fuentes de información disponibles, cuestión que se mencionará con mayor profundidad en párrafos siguientes.

Se busca también, a través de estudios de caso en contextos de extrema pobreza, indagar sobre las respuestas que desarrolla la población afectada para resolver el problema y la intervención del Estado en la materia.

El trabajo está dividido en tres grandes apartados. En un primer momento se detectan los principales enfoques conceptuales que brindan apoyo a la interpretación del problema y se presenta una propuesta metodológica para la medición del fenómeno. En un segundo momento, se analiza la vertiente cuantitativa de la desnutrición infantil en Tucumán, detectando las principales tendencias temporales del problema y su distribución espacial. Luego se complementan estos resultados con estudios de enfoque cualitativo en tres barrios periféricos del Gran San Miguel de Tucumán, definidos a partir de la alta concentración de hogares pobres. En éstos se examinan las relaciones entre el estado nutricional deficitario de los niños con las condiciones socioeconómicas y habitacionales de los hogares en los que residen, buscando profundizar el conocimiento sobre las principales relaciones entre la pobreza como sustento de la desnutrición infantil. En este sentido a través de entrevistas semiestructuradas se profundiza sobre las características que asume la desnutrición en dichos hogares y las acciones que despliegan las familias para enfrentarla, como así también la incidencia de las políticas sociales y sanitarias en esta materia. Finalmente se ensayan algunas conclusiones sobre los análisis realizados.

Con este tipo de examen epidemiológico -que opera sobre la base de la utilización de un Sistema de Información Geográfica (SIG)- y permite aproximarnos a reconocer como se comporta en sus manifestaciones espaciales y temporales el fenómeno de la desnutrición infantil, sus magnitudes y tendencias, se espera contribuir para lograr mayor eficacia y equidad en la prestación de los servicios de salud pública y -por lo tanto- en la gestión de la política social.

\section{UN CONTEXTO TEÓRICO CONCEPTUAL DE INTERPRETACIÓN DEL PROBLEMA}

Se entiende la desnutrición crónica infantil como el resultado fisiopatológico de una ingesta de alimentos insuficientes, que se caracteriza por su continuidad temporal. Esta responde a procesos en los que la capacidad de absorción está disminuida o a defectos metabólicos en los que existe una inadecuada utilización biológica de los nutrientes consumidos (Wanden-Berghe, 2010). Sin embargo, esta insuficiencia no sólo está determinada por factores biológicos, sino que la consideración de las condiciones sociales, económicas y culturales son fundamentales para entender el problema.

Aguirre (2000), al respecto, afirma que las dificultades para acceder a una alimentación adecuada determinan dos fenómenos simultáneos, la desnutrición y la obesidad. Mientras que la 
primera se debe a la insuficiencia de recursos para alimentarse, la segunda se fundamenta en una alimentación inadecuada, con un considerable desequilibrio energético, dado que los recursos limitados permiten generalmente el acceso a los alimentos industrializados, de producción masiva, indiferenciada y barata. La OMS ha llamado a este fenómeno "doble carga de la malnutrición".

En el caso de la infancia la falta de acceso a una adecuada nutrición, sobre todo en los primeros años de vida, tiene graves consecuencias para el crecimiento y desarrollo del niño. Ya a fines de los años '60 era destacado que la desnutrición temprana produce secuelas de mutilación del sistema nervioso y reducción de la capacidad de aprendizaje (Scrimshaw, 1968). Varios estudios demuestran que la falta de nutrientes elementales como hierro y yodo producen deterioro de la función cognitiva provocando un daño cerebral de carácter irreversible (O'Donnell et al., 2007; Hommes et al., 1999; entre otros). En la vida adulta esto se manifiesta a nivel de las habilidades, el perfil emocional y el comportamiento social incidiendo en la productividad y en los niveles de ingreso de vida y de ingreso. La desnutrición en la niñez constituye, asimismo, un mecanismo de transmisión intergeneracional de la pobreza y la desigualdad en tanto produce niveles más altos de morbimortalidad, bajos rendimientos educativos y dificultades para el desempeño laboral en la vida adulta. Queda claro ante estos argumentos la alta carga, en distintos órdenes, que presentan las consecuencias de la desnutrición en la infancia y principalmente, su carácter de irreversibilidad.

Según Oyhenart (op. cit.), los determinantes de la desnutrición pueden clasificarse en inmediatos, subyacentes y básicos. Entre los inmediatos ubica las dietas insuficientes (en cantidad y calidad) y algunas enfermedades; en los subyacentes se encuentran la inseguridad alimentaria, la falta de asistencia médica, el saneamiento deficiente y las malas condiciones higiénicas, entre otros. Al referirse a los determinantes básicos considera la pobreza como el principal, distinguiendo dos niveles de análisis: macro y microinstitucional. En el primero incluye la estructura socioeconómica de un país o región -aquí proponemos el concepto más amplio de territorialización-, la cual condiciona la aparición de enfermedades y su evolución, uno de cuyos desenlaces probables es la muerte. Al interior de la mencionada estructura socioeconómica se distinguen factores ecológicos, político-económicos y del sistema de salud. Por otro lado, pone el foco en los hogares (nivel microinstitucional) en tanto el proceso de aparición y desarrollo de la enfermedad es extremadamente dependiente del contexto familiar. Adquieren un papel decisivo variables sociales como la educación, ingresos, calidad de la vivienda, etc.; y biológicas -fundamentalmente en el caso infantil- como la edad de la madre, dieta, condiciones de paridez, intervalo intergenésico, etc.

Dentro de este último nivel es fundamental considerar las acciones y respuestas de los hogares frente a las necesidades de manutención y reproducción de sus miembros con los recursos disponibles. Raczynski et al. (1995) plantean que son diversos los mecanismos a los que acceden o desarrollan los hogares para asegurar la alimentación diaria como el aumento de los recursos monetarios y no monetarios; el "estirar" los recursos disponibles; apoyarse en los beneficios del sector público; sustentarse en una red social informal; y/o una incorporación al mercado de trabajo de una mayor cantidad de miembros. Éstos constituyen una instancia mediadora en el proceso de salud y enfermedad atenuando o acentuando el problema nutricional.

Cabe destacar que en el presente estudio se entiende a la pobreza, en tanto determinante básico de la desnutrición crónica en la niñez, como una situación estructural en la que se encuentran determinadas familias producto de su particular inserción en la estructura socioproductiva siendo ésta la que posibilita el acceso, en mayor o menor medida, a los bienes y servicios (Moreno, 2009). La pobreza se manifiesta mediante algunas características generales de los hogares tales como sus bajos niveles educacionales de los miembros de dichos hogares, insuficiencias nutricionales, y una mayor precariedad en la actividad laboral, lo que se define a su vez por una pertenencia a ocupaciones de baja productividad, que generan escasos ingresos y 
que impiden satisfacer integralmente sus necesidades más esenciales, materiales y no materiales. Entendemos que en este contexto nace y se desarrolla la desnutrición en la niñez ${ }^{5}$.

A la relación desnutrición infantil - pobreza se incorpora un concepto clave y sinérgico: las infecciones. Estas, por su prevalencia o por la vulnerabilidad inmunológica que generan, agravan el estado nutricional y los riesgos de muerte o mayores secuelas (Scrimshaw, op. cit.).

Dentro de las infecciones resultan especialmente relevantes las infecciones diarreicas agudas (IDA) y las infecciones respiratorias agudas (IRA).

a) IDA y desnutrición

El sinergismo desnutrición-infección se entiende como el efecto potenciado entre ambas patologías. La resistencia a la infección disminuye en el desnutrido y la infección precipita la desnutrición. La agresión combinada y simultánea de ambas situaciones da como resultado una mayor gravedad de la enfermedad. La diarrea inhibe la ingestión normal de alimentos y la absorción de nutrientes, por lo que, es una causa importante de desnutrición infantil.

Sobre la base de estudios publicados por la Sociedad Argentina de Pediatría, puede considerarse que el $100 \%$ de la carga de infecciones intestinales parasitarias son atribuibles al ambiente, y son consecuencia de la falta de un manejo adecuado de las excretas, deficiente provisión de agua potable y malas prácticas de higiene ${ }^{6}$. La transmisión puede ocurrir en el domicilio y el peri-domicilio, la escuela o las áreas de recreación con infraestructura sanitaria inadecuada y suelo contaminado con heces (Ministerio de Salud de la Nación, 2007).

Latham (2002) sostiene que las infestaciones parasitarias, sobre todo las debidas a helmintos intestinales, son muy prevalentes y cada vez más se ha demostrado su efecto adverso sobre el estado nutricional, especialmente en quienes están muy parasitados ${ }^{7}$.

b) IRA y desnutrición

Se sabe que la infección respiratoria afecta y es a su vez afectada por el estado nutricional del paciente. La calidad del aire interior y exterior de las viviendas junto con los factores ambientales está directamente relacionada con las enfermedades respiratorias agudas. El humo de tabaco, la quema de combustibles sólidos y las condiciones de higiene y aislación térmica de la vivienda contribuyen fuertemente a la carga de enfermedad (Ministerio de Salud de la Nación, op. cit. $)^{8}$.

Es ampliamente conocido entonces que las condiciones de sub-alimentación hacen que los niños sean susceptibles a las enfermedades infecciosas. Éstas, a su vez, afectan la utilización biológica de los alimentos, es decir, reducen la capacidad de absorción de los nutrientes por el organismo, lo que refuerza el ciclo de la desnutrición.

En la figura 1 se presenta el esquema propuesto para el análisis de la desnutrición crónica infantil incorporando los niveles y factores mencionados.

\footnotetext{
${ }^{5}$ Numerosos estudios (Aguirre, 2000; Oyhenart, 2007 y 2008; Calvo, 2005; Durán et al., 2009; Bolzán et al., 2009; UNICEF, 2011) evidencian las situaciones de pobreza como causa básica de la desnutrición, al punto de considerar las mediciones de pobreza como la Línea de Indigencia como estimaciones de desnutrición por la incapacidad de acceder a los alimentos básicos que dicho indicador refleja. Todo esto en un contexto de creciente distancia entre el precio de los alimentos y los ingresos monetarios de los sectores populares (Aguirre, 2005; Herkovits, 2007; FAO, 2014).

${ }^{6}$ Es conocida la fuerte relación entre parasitosis, infección y desnutrición infantil. Al respecto, sostenía Martínez Gómez (1969) el especial papel que juega la especie humana como hospedador intermediario de un cestodo parásito intestinal del perro, Echonococcus granulosus, agente causal de la hidatidosis humana.

${ }^{7}$ Estudios recientes pusieron de manifiesto la asociación entre poliparasitismo y desnutrición infantil, de mayor incidencia, de acuerdo a los casos estudiados, en áreas periurbanas (Cesani et al., 2007), donde se localizan los sectores sociales peor posicionados de la ciudad.

${ }^{8}$ Cfr. Penié (2000).
} 
FIGURA 1

Factores que inciden en la aparición y desarrollo de la desnutrición en la niñez

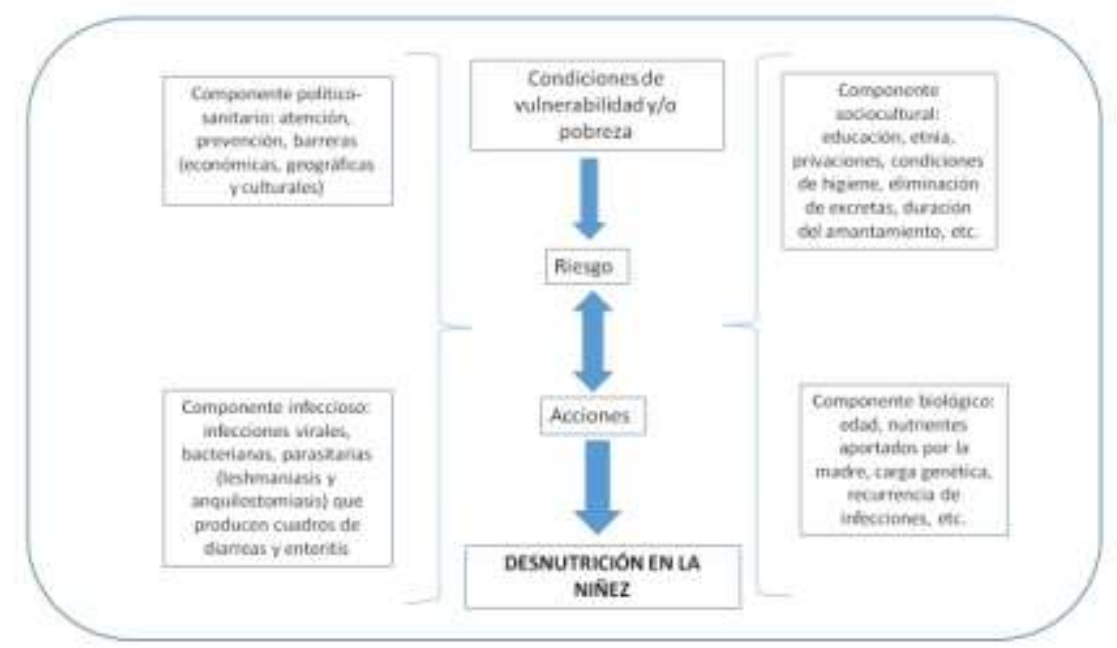

Fuente: tomado de Longhi, 2014.

Asimismo, el enfoque que se diseño en esta propuesta se sustenta sobre una perspectiva extrema, ya que considera solo el extremo del problema, al tomar como indicador la muerte infantil por desnutrición. En tal sentido puede advertirse en la figura 2 la extremidad mencionada que reviste la tasa, ya que incluye las muertes registradas en las actas de defunción bajo la causa "desnutrición", soslayando del análisis todas aquellas muertes relacionadas con desnutrición y registradas con otra patología, así como los casos de desnutrición que no necesariamente terminaron con un desenlace fatal. La Figura 2 ayuda a ilustrar ese carácter extremo junto a los diferentes indicadores asociados según el estadio de avance de la patología; en esta propuesta, como se mencionó, consideramos el desenlace fatal del desarrollo de la patología según la figura mencionada.

FIGURA 2

Dinámica de la desnutrición e indicadores asociados

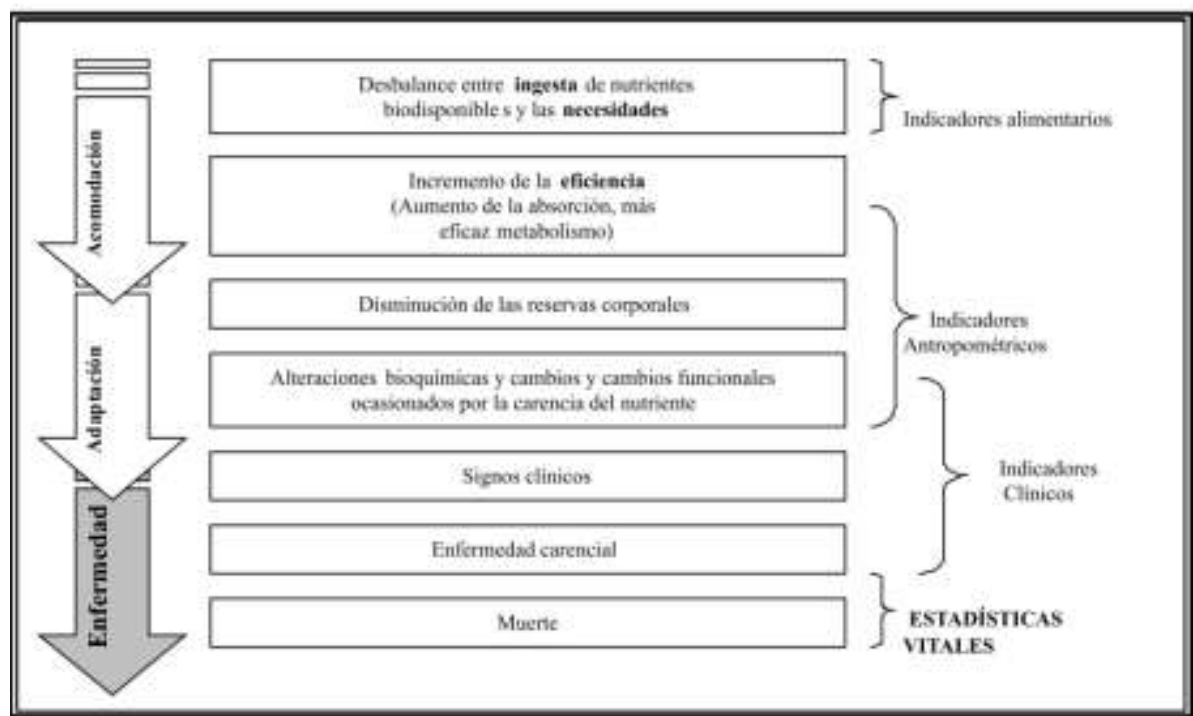

Fuente: Carmuega et al., 2000:7. 


\section{UNA APROXIMACIÓN METODOLÓGICA: LAS CAUSAS DIRECTAS Y LAS CAUSAS CONTRIBUTIVAS DE LA DESNUTRICIÓN EN LA NIÑEZ}

El registro de la desnutrición infantil en Argentina no ha sido sistemático, preciso y representativo, característica que vuelve complejo su estudio y seguimiento. La primera Encuesta Nacional de Nutrición y Salud se realizó en el año 2005 distinguiendo a la desnutrición infantil como un importante problema de salud pública para el país. No obstante, hasta el presente no se ha relevado nueva información que permita detectar las magnitudes y tendencias del problema.

Existen, sin embargo, los registros de mortalidad producidos por la Dirección de Estadísticas e Información de Salud del Ministerio de Salud de la Nación en el marco de la producción del Programa Nacional de Estadísticas de Salud. Si bien representan como fuente de información el cuadro situacional más trágico del proceso de salud/enfermedad por el que discurre un individuo, permite aproximarse al conocimiento anual del fenómeno a partir de análisis de determinadas causas de muerte.

En este sentido, para cumplir con los objetivos propuestos, se construyeron dos tasas de mortalidad infantil por desnutrición, una según causas directas y otra según causas asociadas o contributivas del cuadro de desnutrición. La primera relaciona la cantidad de muertes registradas por anemias y deficiencias de la nutrición con respecto a la población menor de cinco años del área seleccionada, expresada cada mil menores'.

La segunda tasa de mortalidad construida se articula con el clásico estudio de Puffer (1970) donde sostenía el carácter contributario y sinérgico de la desnutrición sobre muchas otras dolencias. De allí que se proponga construir un indicador de causas asociadas a la desnutrición en la niñez a partir de la inclusión de las infecciones diarreicas agudas (IDA) y las infecciones respiratorias agudas (IRA), que -de acuerdo a las experiencias obtenidas en muchos países estudiados-, son las patologías más vinculadas con la desnutrición entre los 0 y 59 meses de $\operatorname{vida}^{10}$.

\footnotetext{
${ }^{9}$ De acuerdo con la Clasificación Internacional de Enfermedades (CIE 10) integran la categoría "desnutrición" las siguientes patologías: anemias por falta de hierro (D50), anemia por deficiencia de vitamina B12 (D51), anemia por deficiencia de folatos (D52), otras anemias nutricionales (D53), Kwashiorkor (E40), marasmo nutricional (E41), Kwashiorkor marasmático (E42), desnutrición proteinocalórica (E43-E46), deficiencia de vitamina A (E50), deficiencia de tiamina (E51), pelagra (E52), deficiencia de otras vitaminas del grupo B (E53), deficiencia de ácido ascórbico (E54), deficiencia de vitamina D (E55), otras deficiencias de vitaminas (E56), deficiencia dietética de calcio (E58), deficiencia dietética de selenio (E59), deficiencia dietética de zinc (E60), deficiencia de otros elementos nutricionales (E61), otras deficiencias nutricionales (E63) y secuelas de la desnutrición y de otras deficiencias nutricionales (E64).

${ }^{10}$ Las infecciones diarreicas son patologías del tracto digestivo ocasionadas por bacterias, virus o parásitos, cuyo principal síntoma es la diarrea, las cuales son más frecuentes en verano debido a las mayores temperaturas que favorecen la diseminación de las bacterias que las provocan. De acuerdo a la Organización Mundial de la Salud las enfermedades diarreicas son la segunda mayor causa de muerte de niños menores de cinco años. Integran las infecciones diarreicas agudas las siguientes patologías: cólera (A00), fiebres tifoidea y paratifoidea (A01), otras infecciones debidas a salmonella (A02), shigelosis (A03), otras infecciones intestinales bacterianas (A04), otras intoxicaciones alimentarias bacterianas (A05), amebiasis (A06), otras enfermedades intestinales debidas a protozoarios (A07), infecciones intestinales debidas a virus y a otros organismos especificados (A08), diarreas y gastroenteritis de presunto origen infeccioso (A09), septicemias (A40-41) y las infecciones bacterianas de sitios no especificados (A49). Por otro lado, las infecciones respiratorias agudas constituyen el principal motivo de consulta ambulatoria en niños y adultos, especialmente durante los meses de más bajas temperaturas. Constituyen un grupo importante de enfermedades causadas tanto por virus como por bacterias. Generan una alta morbilidad en personas de cualquier edad; pero son muy frecuentes antes de los cinco años de edad y a partir de los 65 años. Las IRA son la primera causa de consulta ambulatoria, y se ubican entre las primeras cinco causas de hospitalización y de mortalidad en la población general de Argentina. Integran el grupo IRA las siguientes patologías: rinofaringitis aguda (resfriado común) (J00), sinusitis aguda (J01), faringitis aguda (J02), amigdalitis aguda (J03), laringitis y traqueitis agudas (J04), laringitis obstructiva aguda (crup) y epiglotitis (J05), infecciones agudas de las vias respiratorias superiores, de sitios múltiples
} 
El conjunto de estas patologías como causas de muerte permitiría aproximarse -con cierta modestia- a las causas básicas (muchas veces ignorada) y de esta manera aproximarse con cierto grado de certeza la magnitud de la desnutrición como desenlace fatal. No obstante, constituye un abordaje extremo como se mencionó anteriormente, que solo considera la mortalidad por desnutrición (ya sea de modo directo o asociado) soslayando la carga que produce la enfermedad con sus notables consecuencias en los derroteros educativos, laborales, económicos, afectivos, entre otros, de los afectados.

Las fuentes que brindan esta información en Argentina corresponden, como ya se mencionó anteriormente, al Programa Nacional de Estadísticas de Salud, dependiente de la Dirección Nacional de Estadísticas de Salud del Ministerio de Salud de la Nación. Si bien ésta propuesta metodológica solo detecta una pequeña magnitud del problema, en tanto excluye otras manifestaciones como la morbilidad, permite inferir el adonde se localiza el problema y una estimación de su magnitud. Dicha información resultaría esencial para la formulación de políticas públicas, entendiendo que la mortalidad es el reflejo final de determinadas condiciones de vida.

Una segunda estrategia metodológica, de base cualitativa, operó seleccionando primeramente tres casos de estudios según alta concentración de pobreza a partir de la aplicación de la intensidad del Índice de Privación Material de los Hogares (IPMH), el cual constituye un indicador elaborado por el Instituto Nacional de Estadísticas y Censos, sobre la base de la información del Censo de Población, Hogares y Vivienda del 2001, que identifica diferencias al interior de los hogares pobres. Se obtiene a partir de la combinación de dos indicadores: el de condiciones habitacionales (CONDHAB) y el de capacidad económica del hogar (CAPECO). El primero combina características de los materiales constructivos y de la infraestructura sanitaria que componen la vivienda (hogares con piso de tierra, techos sin cielorraso -de chapa, fibrocemento, plástico, cartón, caña, tabla, paja con barro, paja sola- y que carecen de inodoro con descarga de agua). El segundo se aproxima al nivel de ingresos del hogar combinando los años de educación formal aprobados por los perceptores de ingresos y la cantidad total de miembros del hogar. Según el tipo de privación, distingue cuatro categorías de hogares: a) hogares sólo con privación de recursos patrimoniales; b) hogares sólo con privación de recursos corrientes; c) hogares con privación convergente -combinan carencias patrimoniales y coyunturales-; y d) hogares sin privación (Gómez et al., 2003). La medida intensidad reconoce la gravedad de las privaciones en el conjunto de hogares carenciados (Bolsi et al., 2009).

Una vez detectadas las áreas de mayor pobreza en el Gran San Miguel de Tucumán (Aglomerado que oficia de capital de la provincia y que reunía en 2001 el 55\% de la población provincial) se seleccionaron tres barrios denominados Costanera Norte, Juan Pablo II y Villa Muñecas Norte para analizar las condiciones habitacionales, socioeconómicas y nutricionales de su población. Allí se realizaron entrevistas semiestructuradas a una muestra aleatoria de hogares -en total ciento diez entrevistas que representan aproximadamente el 10\% de los hogares de cada uno de los barrios-. En aquellos hogares pobres en los que se detectó problemas de desnutrición en la niñez se indagaron las características que asume el problema, las acciones y respuestas de las familias afectadas y la incidencia de las políticas sociales y sanitarias vigentes.

Se recabaron, asimismo, datos sobre el estado nutricional de la infancia a partir de relevamientos realizados en el año 2009 por los Centros de Atención Primaria de la Salud (CAPS) de las áreas de estudio, pertenecientes al Sistema Provincial de Salud (SIPROSA) ${ }^{11}$. Éstos se confeccionan a partir de resúmenes de ronda realizados por los agentes sanitarios de dichos centros, en estos casos corresponden con los CAPS Villa Muñecas, Santa Rosa de Lima, Eva Duarte y Costanera Norte. Se utilizan los datos sobre estado nutricional de niños de hasta 14 años, particularmente los que se encuentran en estado de desnutrición y los grados o niveles de gravedad de la enfermedad.

o no especificados (J06), influenzas (J10-11), neumonías (J12-16, J18), bronquitis (J20), bronquiolitis (J21) e infecciones agudas no especificada de las vías respiratorias inferiores (J22).

${ }^{11}$ El alcance temporal de la fuente de información se debe a que en el año 2010 se realizaron las gestiones ante las autoridades del área de salud para acceder a las mismas consiguiendo las correspondientes al año 2009. 


\subsection{LAS FUENTES DE INFORMACIÓN}

En este trabajo se utilizaron estadísticas vitales de mortalidad y entrevistas semiestructuradas a familias residentes en barrios de extrema pobreza.

Con respecto a las estadísticas vitales -fuentes susceptibles de presentar mayor distorsión y problemas de confiabilidad- es preciso mencionar que la cobertura de los hechos vitales presenta, en América Latina, grandes diferencias que varían de país en país. Argentina se caracterizó por un buen sistema de registro de datos, aunque existen singulares distancias al interior de las provincias. Estos errores pueden no afectar significativamente la medición del nivel del fenómeno, pero sí plantean algunas limitaciones relativas al análisis de sus características (Díaz Muñoz, 1995).

Alazraqui (2005) expresa que, aunque el registro de nacimientos y defunciones es obligatorio en el país, no alcanzan los incentivos ni los controles correspondientes por parte de las autoridades a fin de dar lugar a la mayor cobertura posible. Por otra parte, como las oficinas encargadas del registro de los hechos vitales pertenecen a la jurisdicción provincial, de ello se deriva la diferente calidad y las limitaciones de los datos según la provincia considerada. Entre los problemas que este autor menciona se encuentran: los registros asistemáticos, la ausencia de soporte magnético, bases de datos sin reconocimiento formal de la institución, suposiciones e incoherencias entre bases de datos semejantes, entre otros problemas (Alazraqui, 2005).

La presente investigación utiliza información sobre nacidos vivos y muertes en menores de cinco años por causas específicas correspondientes al período 2000-2013 en Tucumán y relevadas en un nivel de desagregación geográfica departamental. El registro de la causa básica de muerte es un dato de suma importancia dado que constituye la principal fuente para obtener información sobre la mortalidad de la población y las características de su perfil epidemiológico, como así también el grado de avance en su transición epidemiológica. A su vez, resulta esencial para la formulación de programas y políticas de salud.

De acuerdo a la Clasificación Internacional de Enfermedades (CIE10) se entiende como causa de defunción a todas aquellas enfermedades, estados morbosos o lesiones que causaron la muerte o que contribuyeron a ella y las circunstancias del accidente o de la violencia que produjeron ciertas lesiones. Esta definición no incluye síntomas ni modos de morir tales como paro cardíaco o insuficiencia respiratoria, cuando son el resultado final de un proceso de enfermedad. El porcentaje de causas de muerte mal definidas de alguna manera, como plantean Chackiel (1987) y Jaspers-Faijer et al., (1994), precisa la magnitud del subregistro, ya que existe una relación directa entre subregistro y causas mal definidas. Asimismo, la calidad de esta variable es heterogénea por región y provincia y los altos niveles de error, en ciertos casos, denegarían la posibilidad de su utilización.

No obstante, en el caso especifico de la provincia de Tucumán podemos sostener que el registro de las estadísticas vitales en general y de las causas de muerte en particular presentan un alto grado de confiabilidad, ya que sólo el 5\% de las defunciones ocurridas integra el grupo de "Signos síntomas y estados morbosos mal definidos" (R00-R99 de la CIE 10), siendo el valor nacional en idéntica categoría del 7.5\%. Estos cálculos junto al examen de la información justifican el uso de la fuente y el análisis epidemiológico aquí propuesto.

\section{LA PROVINCIA DE TUCUMÁN COMO CUNA DE LA DESNUTRICIÓN INFANTIL}

Existen notorias evidencias para sostener que la desnutrición infantil constituye un problema histórico para la provincia de Tucumán. A fines del siglo XIX se publicaba el clásico libro de Rodríguez Marquina sobre la mortalidad infantil en la provincia de Tucumán. En el, sin hacer uso del término "desnutrición", ponía de manifiesto las características extremas que asumía el problema alimentario en la provincia en aquella época. Mencionaba al respecto:

"[...JViene después de esto el sistema miserable de alimentación de las madres que no es posible presumir produzca leche abundante y de buena calidad, y como las criaturas lloran de hambre pronto principia a sustituirse aquella con caldo de 
mazamorra primero, con sopas de pan después, y no tardan en dar a niños que apenas tienen las señales de una próxima dentición un pedazo de carne asada que las muelas de sus propios padres repudiarían”. (Rodríguez Marquina, [1899] (2012: 28).

Este contexto problemático es respaldado ya a mediado de siglo XX por Baldrich (1944). Afirmaba el autor:

"[...] En nuestra provincia existe el problema del infraconsumo y la superproducción. Tenemos la injusticia de grandes cantidades de alimentos sin distribuir, junto a grandes masas de población económicamente débil y deficientemente alimentada. En todo el territorio de la provincia miles de niños presentan los estigmas del raquitismo [...]". Baldrich (1944: 41).

En el año 2002, como ya se mencionó, el problema de la desnutrición infantil en Tucumán tomó una repercusión inusitada a través de numerosos casos divulgados por medios periodísticos ${ }^{12}$. Investigaciones más recientes referían que el problema de la desnutrición infantil tucumana podría ser más severo aún en cualquiera de las otras provincias norteñas ${ }^{13}$.

En el mismo sentido Medwid (2008) afirmaba que durante el año 2002 Tucumán, la provincia más pequeña de la Argentina, se hacía visible en el contexto nacional e internacional a partir de titulares como "los chicos del país del hambre", "Detectan unos 11790 chicos desnutridos en Tucumán", o "Desnutrición infantil extrema en Villa Quinteros, sur de Tucumán". Asimismo, sostenía Demonte (2011) que los medios de comunicación se erigieron en aquel entonces como los actores protagónicos en el proceso de construcción del problema de la desnutrición infantil en el contexto crítico de 2001. A partir de ellos, la cuestión alimentaria y la malnutrición infantil cobraron alta visibilidad social y política. El discurso periodístico, según Demonte (op. cit.) sostenía un enfoque de la desnutrición como si fuera una enfermedad infectocontagiosa, que se propaga, se extiende y contra la que hay que luchar, basándose en la conmoción y en la compasión mas que en la argumentación o la información epidemiológica.

La Encuesta Nacional de Nutrición y Salud, realizada entre 2004 y 2005 brindaba luz sobre un problema en el que la prensa habría mostrado su lado más "amarillista" y existía poca información científica relevante para contrastarlo. Dicha encuesta mostraba que, en el caso tucumano, el $17 \%$ de los niños presentaban problemas de acortamiento, con lo cual era manifiesto que los niños residentes en el Norte Argentino en general y en Tucumán en particular no han podido modificar la tendencia secular de su crecimiento (Bolzán et al., 2009).

Existían notorias evidencias para sostener lo estructural del problema de la desnutrición infantil en Tucumán. Sin embargo, más allá del diagnóstico mencionado, se desconocían aspectos centrales de la desnutrición crónica infantil en Tucumán relacionados con la evolución

\footnotetext{
${ }^{12}$ Pueden verse consultarse en su versión online las siguientes notas: http://www.lanacion.com.ar/451228-alarmantes-cifras-de-desnutricion-infantil, [26 de julio de 2011] http://edant.clarin.com/diario/2003/02/19/s-03301.htm, [26 de julio de 2011] http://edant.clarin.com/suplementos/zona/2003/11/16/z-659738.htm, [26 de julio de 2011] http://www.pagina12.com.ar/diario/elpais/1-13623-2002-12-01.html, [26 de julio de 2011] http://www.pagina12.com.ar/diario/sociedad/3-5341-2002-05-20.html [26 de julio de 2011] http://www.nytimes.com/2003/03/02/world/once-secure-argentines-now-lack-food-andhope.html:http:/www.nytimes.com/2003/03/02/world/once-secure-argentines-now-lack-food-andhope.html?scp=1\&sq=child\%20malnutrition\%20tucuman\&st=cse [26 de julio de 2011] http://www.lemonde.fr/cgibin/ACHATS/acheter.cgi?offre=ARCHIVES\&type item=ART ARCH 30J\&objet id=781745 $\left[\begin{array}{lll}26 & \mathrm{de}\end{array}\right.$ julio de 2011] http://www.lagaceta.com.ar/nota/28498/Información_General/Son-19-niños-murierondesnutricion.html[26 de julio de 2011] http://www.abc.es/hemeroteca/historico-29-12-2002/abc/Ultima/fallece-un-bebe-de-cuatro-meses-pordesnutricion-en-la-provincia-de-tucuman 152710.html [26 de julio de 2011] http://www.abc.es/hemeroteca/historico-01-12-2002/abc/Internacional/la-desnutricion-infantil-es-unalacra-existente-desde-hace-decadas-en-tucuman_146979.html [26 de julio de 2011] http://www.estadao.com.br/arquivo/economia/2002/not20020826p36469.htm [26 de julio de 2011] ${ }^{13}$ Cfr. Longhi (2012).
} 
de su magnitud, la tendencia temporal del proceso, su distribución espacial, y, derivado de una vertiente cualitativa de análisis, algunas características relacionadas con las acciones familiares y la respuesta estatal ante la presencia del problema en contextos de pobreza.

Estos tópicos se desarrollan en los siguientes apartados a partir del abordaje metodológico precisado.

\section{CAMBIOS Y TENDENCIAS DE LA DESNUTRICIÓN EN LA NIÑEZ TUCUMANA EN LA TRANSICIÓN DEL SIGLO XX AL SIGLO XXI}

En la figura 3 se observa la evolución que tuvo la desnutrición en la niñez como causa directa de muerte entre 1994 y 2012. Es notorio el marcado descenso que ha evidenciado la tasa, no sin mostrar respuestas a las crisis socioeconómicas que vivió la provincia, tales como la crisis de 2001-02, de la cual tomaran eco los principales periódicos nacionales e internacionales. No obstante, puede observarse que los valores de la mortalidad por desnutrición eran aun mayores en años previos a dicha crisis. En el año 1994 por ejemplo, los registros triplicaban los valores de 2001/02, con una tasa de mortalidad por desnutrición que alcanzaba al 0.14 por mil menores de cinco años; esto implicaba que sólo ese año murieron por desnutrición en Tucumán veinte niños menores de cinco años. Se observa, además, a partir de la crisis de 2001-02, una recuperación de la tendencia descendente con sutiles picos alrededor de 2008/09.

FIGURA 3

Provincia de Tucumán. Tasa de desnutrición en la niñez por causas directas. 1994-2012

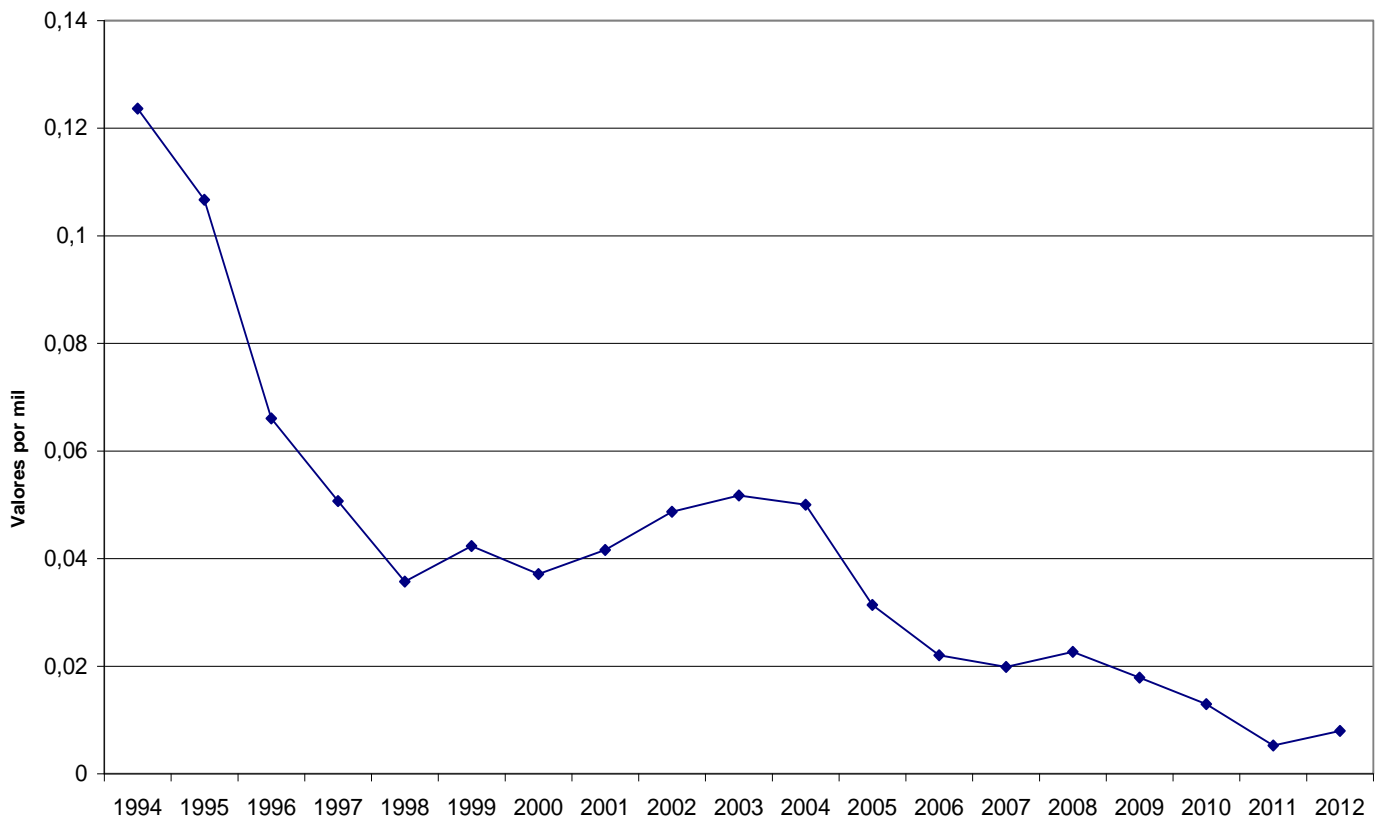

Años

Fuente: Programa Nacional de Estadísticas de Salud. Censos Nacionales de Población, Hogares y Viviendas 2001 y 2010

Por otro lado, encontramos una vertiente de análisis complementaria en las causas de muerte asociadas (o contributivas) a la desnutrición en la niñez, las cuales mostraron un panorama más complejo del problema (figura 4). En primer lugar, se observa que alcanza valores más elevados que la tasa de mortalidad por causas directas. Esta afirmación queda demostrada con valores de las primeras que como mínimo triplican los registros de las causas directas. Es evidente también un comportamiento que, si bien tiende al descenso, presenta algunos picos notorios, principalmente alrededor de los años 2002 y 2007. Es llamativa también una tendencia ascendente que se inicia en 2010 y hasta 2012 al menos se ha sostenido. Cuando 
descomponemos esta tasa en su componente diarreico (IDA) o respiratorio (IRA) se observa con claridad el predominio de las diarreas hasta el año 2005, momento a partir del cual las infecciones respiratorias ocuparon un mayor protagonismo en la mortalidad contributiva a la desnutrición. Asimismo, de los picos mencionados en 2001, 2007 y 2012, se encuentra una asociación en el primero de ellos con las IDA's, en cambio, en los picos sucesivos, son las IRA's las que explicarían dicho comportamiento.

FIGURA 4

Provincia de Tucumán. Tasa de desnutrición en la niñez por causas asociadas. 1994-2012

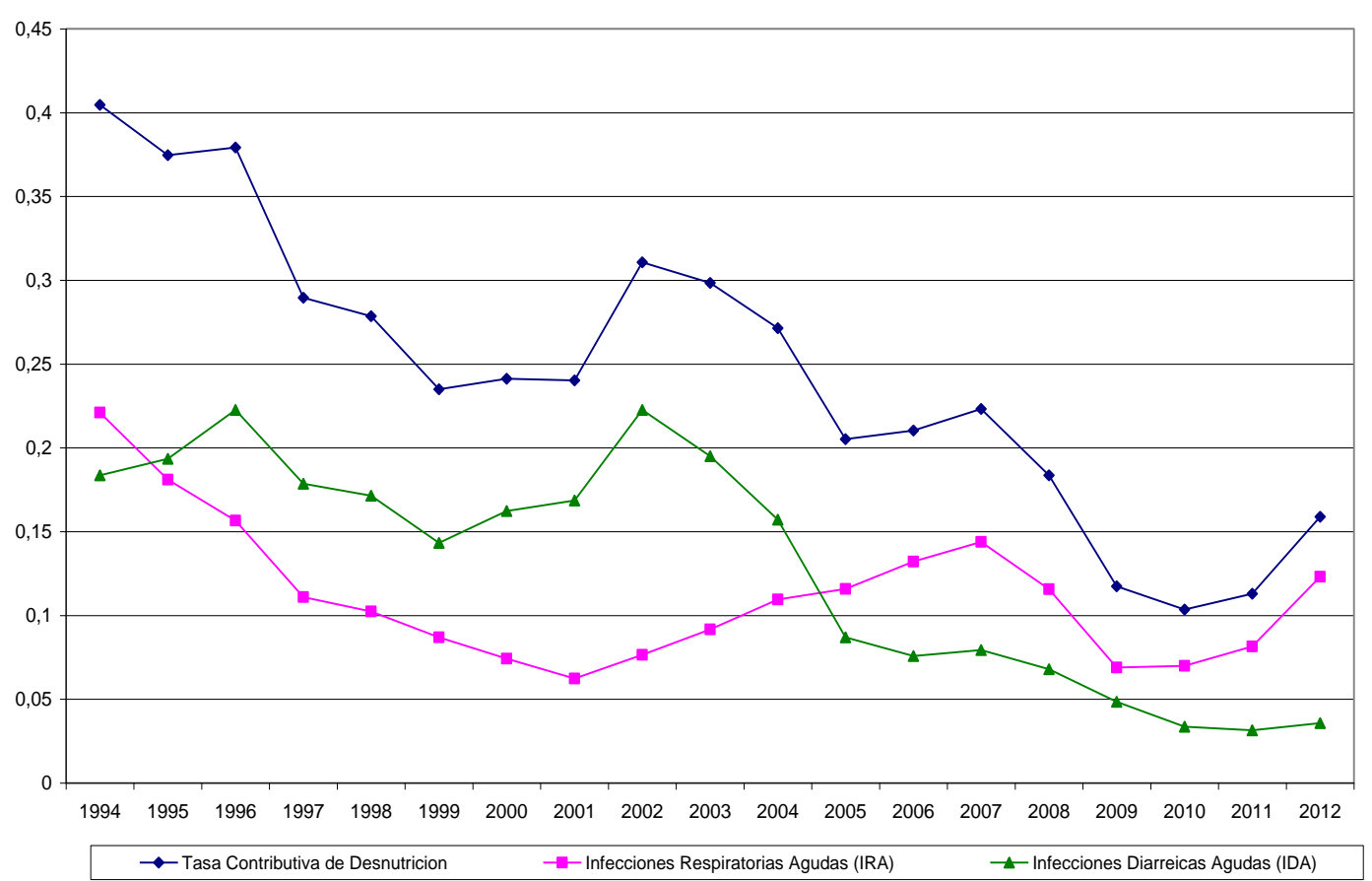

Fuente: Programa Nacional de Estadísticas de Salud. Censos Nacionales de Población,

Hogares y Viviendas 2001 y 2010

De modo complementario a la tendencia temporal se analiza la distribución espacial de la muerte por desnutrición en la niñez tucumana a nivel departamental, observándose por un lado las causas directas y por otro las causas de muerte contributivas. Se definieron para ello cinco quinquenios incluidos en el periodo de análisis. El primer quinquenio se ubica en el periodo 1994/98, el segundo en el quinquenio que va de 2001 a 2005 y el tercer periodo abarca desde 2008 a 2012, y se definieron cuatro categorías cartográficas que se replican en cada distribución identificadas por cuartiles, a los que se suma la categoría inicial que indica la ausencia de muertes en la niñez en esos departamentos.

Bajo este enfoque, la figura 5 presenta dicha distribución. Se observa un panorama donde domina más la variación que la estabilidad. Al igual que en el caso anterior, hay notorias diferencias entre las causas directas y las contributivas.

En el caso de las causas directas de muerte por desnutrición en la niñez se observa en el primer quinquenio que los valores más altos se localizan en Chicligasta, Río Chico, Alberdi, La Cocha y Graneros, mientras se observa ausencia de casos en Simoca, leales y Trancas. En el segundo quinquenio se observan dos casos particulares de importante variación, tal como Trancas con un notorio empeoramiento y Río Chico con una sustancial mejora. Finalmente, en el tercer quinquenio analizado, los valores más elevados se localizan en Alberdi, Río Chico, Chicligasta, Capital, y Burruyacu, mientras en el resto del territorio se observa la inexistencia de casos de muerte directos por desnutrición. Como complemento se presenta la distribución espacial de las causas de muerte contributivas a la desnutrición en la niñez. Como se ha mencionado anteriormente, detentan registros más elevados que en el caso de las causas directas, lo cual conlleva que en los primeros quinquenios las variaciones espaciales 
departamentales sean mínimas. No obstante, en el tercer quinquenio sí se destaca la ausencia de casos en Tafí del Valle y Simoca, como así también un incremento de su concentración en los departamentos de Graneros y Yerba Buena.

Queda claro que en las casi dos décadas que van desde 1994 a 2012, bajo distintos signos políticos e ideológicos, la desnutrición infantil en Tucumán, si bien ha disminuido, su incidencia no ha sido erradicada. En este lapso murieron en la provincia ciento diez niños directamente por desnutrición. Se desconoce, no obstante, la cantidad de aquellos que padeciendo la enfermedad no fallecieron, pero sobrellevan secuelas que afectaran, como ya se expuso, su potencial desarrollo e inserción socio-productiva-. Desconocemos también aquellos casos de desnutrición infantil que no se registraron o que fueron registrados bajo otra causa. En este contexto determinadas causas probablemente hayan contribuido al cuadro de desnutrición existente en la provincia, tal es así que las infecciones diarreicas agudas desencadenaron la muerte de trescientos treinta y siete niños y las infecciones respiratorias agudas se llevaron a la muerte a doscientos ochenta y ocho niños también. Cabe aclarar finalmente que el departamento que incluyó la mayor cantidad de estos casos fue el departamento Capital (27\% de las defunciones en la niñez directas por desnutrición, 26\% de las IDA's y 29\% de las IRA's).

En este contexto, consideramos estas magnitudes de gran trascendencia e importancia para la aplicación de políticas públicas efectivas y centralizadas.

\section{FIGURA 5}

Provincia de Tucumán. Distribución espacial según quinquenios de la tasa de mortalidad en la niñez por desnutrición (causas directas y contributivas). 1994 - 2012

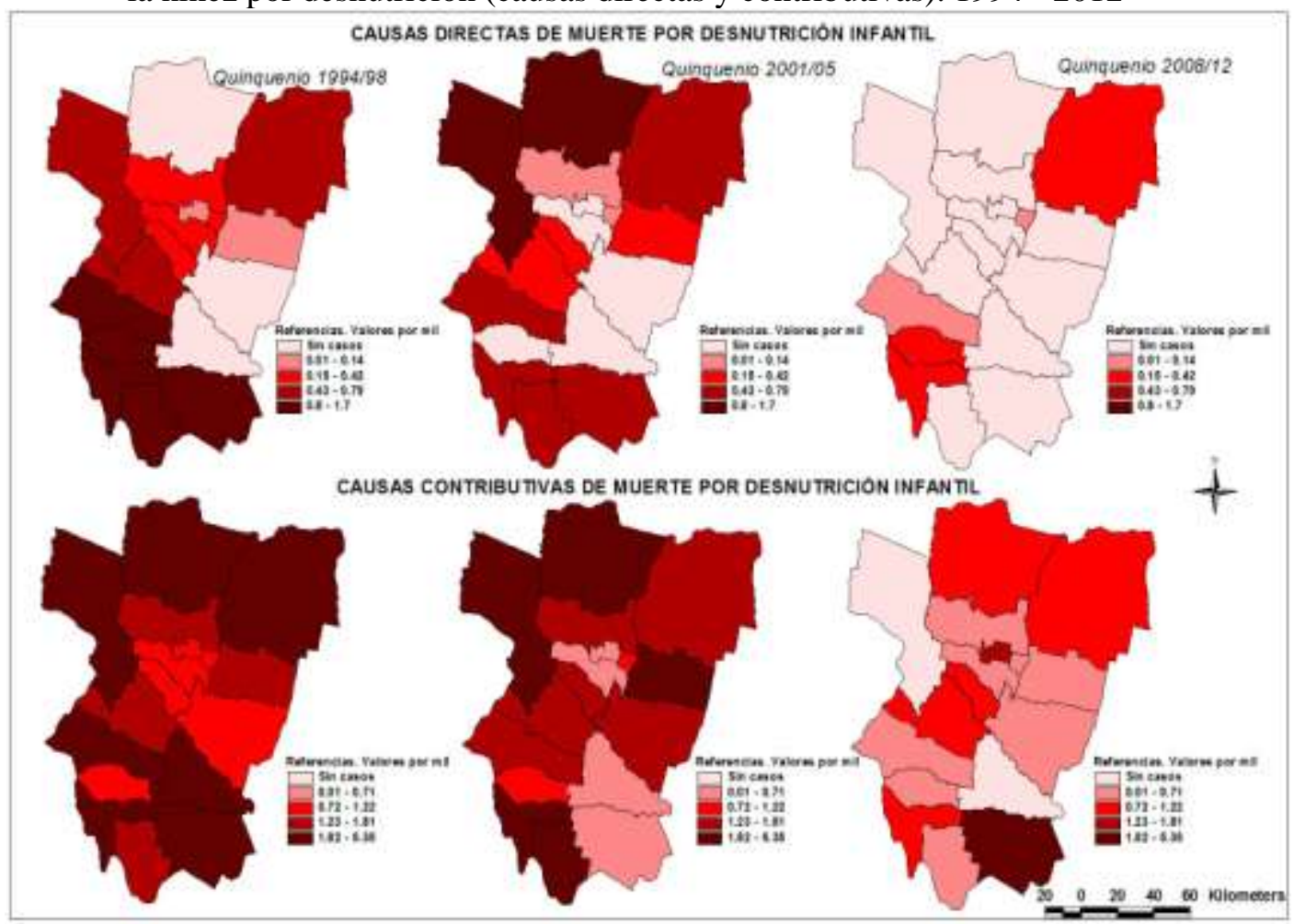

Fuente: Programa Nacional de Estadísticas de Salud. Censos Nacionales de Población, Hogares y Viviendas 2001 y 2010. Elaboración: Laboratorio de Cartografía Digital. Instituto Superior de Estudios Sociales. CONICET - UNT.

\section{POBREZA Y DESNUTRICIÓN INFANTIL: ESTUDIOS DE CASO EN GRAN SAN MIGUEL DE TUCUMÁN}

El aglomerado Gran San Miguel de Tucumán (GSMT) comprende un conjunto de localidades distribuidas entre cinco departamentos de la provincia, incluyendo distintos 
municipios y comunas rurales, cuyo núcleo es la capital provincial. Su población alcanzaba en el año 2010, según el Instituto Nacional de Estadística y Censos (INDEC), unos 839.904 habitantes. Si bien es la ciudad intermedia más importante del Norte Grande Argentino, su crecimiento y desarrollo no ha redundado en bienestar para su población. El estudio de Bolsi y Mignone (2009) identificaba al GSMT en el grupo de aglomerados de esta región que concentra, utilizando el IPMH, mayores niveles de pobreza convergente y la más baja proporción de hogares sin privación.

El cálculo de la intensidad del IPMH, como se observa en el mapa 2, detecta que en la periferia del aglomerado prevalece un cordón de pobreza crítica, junto a la presencia de algunas "islas de pobreza", con umbrales que superan el 50\% de intensidad. Conjeturamos que en este contexto de elevadas privaciones la desnutrición infantil crónica, entendida como la baja talla para la edad, podría constituir una característica de estas poblaciones. Por otro lado, si bien los niveles de privación mejoran en los sectores más próximos al área central, éstos igualmente siguen concentrando una significativa presencia de hogares con severas privaciones. Finalmente, la mayor cantidad de hogares sin privaciones se concentran en el área central y en el sector oeste del aglomerado.

Dentro de las áreas de mayor pobreza en la ciudad, definidas por la última categoría cartográfica, se seleccionaron tres barrios para los estudios de caso (Ver Figura 6) ${ }^{14}$. Estos barrios tienen en común, según la constatación de entrevistas y otras fuentes, la persistencia de la pobreza durante -al menos- medio siglo.

FIGURA 6

Gran San Miguel de Tucumán. Intensidad del Índice de Privación Material de los Hogares. 2001

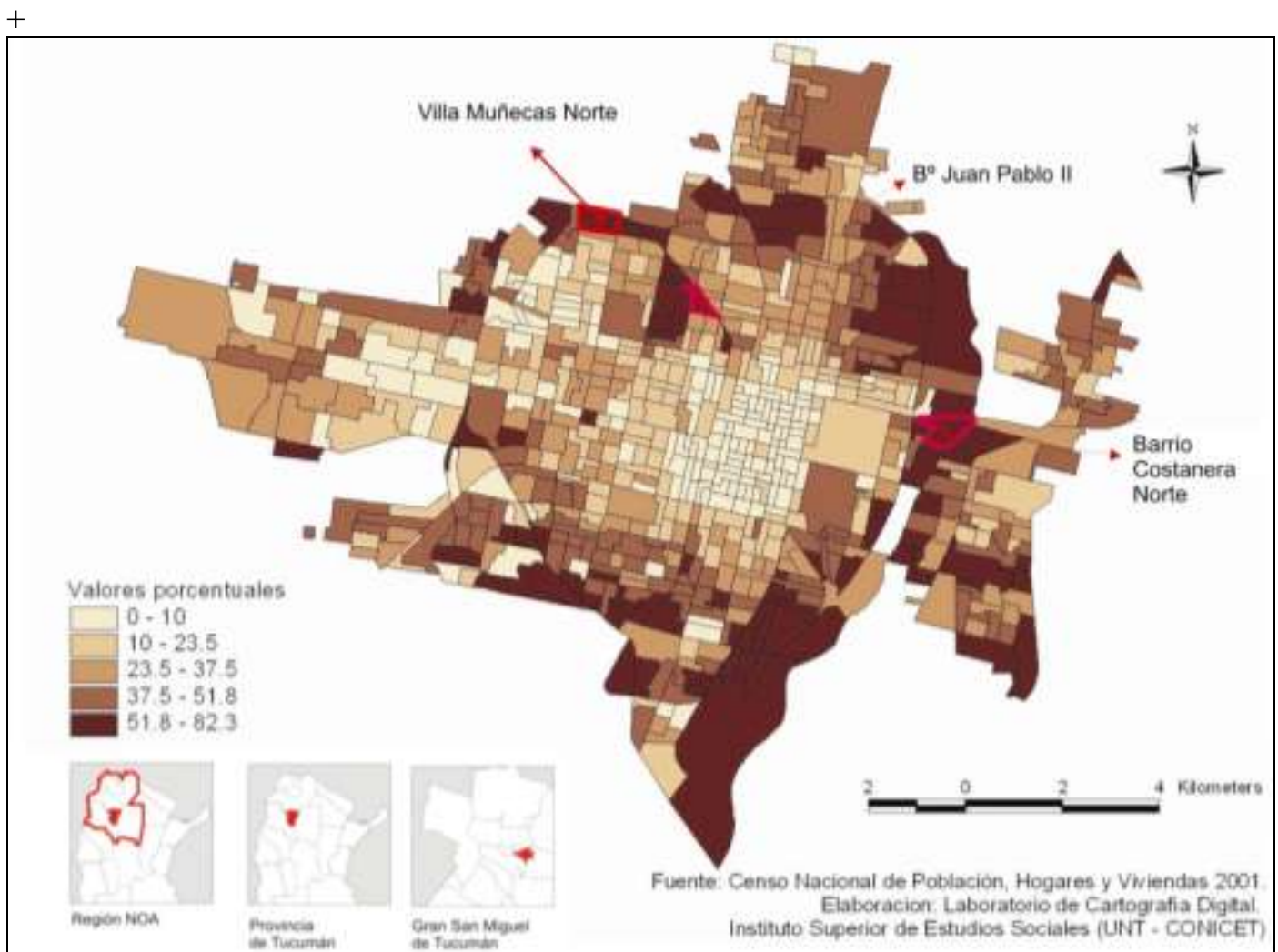

En las entrevistas semiestructuradas a los hogares se pudo constatar el atributo de pobreza que los caracterizan, dado que la precariedad e informalidad habitacional estructuran la pobreza en dichos territorios. Son mayoritarias las viviendas con deficiencias edilicias, siendo significativa la presencia de casillas y ranchos. Pese a la antigüedad en la que residen en los barrios de referencia, aproximadamente la totalidad de los hogares aun no son propietarios de

\footnotetext{
${ }^{14}$ Dichos barrios se seleccionaron con el criterio de superar el umbral del 51,8\% de intensidad del IPMH.
} 
los terrenos donde se asientan sus viviendas (tabla 1). Los servicios cloacales todavía no están extendidos, alcanzando sólo a la mitad de los hogares en el caso de uno de los barrios. El hacinamiento a su vez tiene un comportamiento variable, pero adquiere un nivel significativo en los barrios Costanera Norte (50\%) y Juan Pablo II $(30 \%)^{15}$. Se agrega también la falta de acceso de la población a ciertos servicios básicos, como el gas natural y la pavimentación, y una accesibilidad limitada a otros, como el transporte y alumbrado público y la recolección de residuos. Queda clara ante esta caracterización el contexto de pobreza sobre el que se asientan los hogares entrevistados.

TABLA 1

Barrios seleccionados del GSMT. Características de vivienda

\begin{tabular}{|c|c|c|c|c|}
\hline $\begin{array}{c}\text { Características } \\
\text { de la Vivienda }\end{array}$ & Variables & $\begin{array}{c}\text { Villa } \\
\text { Muñecas } \\
\text { Norte }\end{array}$ & $\begin{array}{r}\text { Juan } \\
\text { Pablo II }\end{array}$ & $\begin{array}{r}\text { Costan } \\
\text { era Norte }\end{array}$ \\
\hline \multirow{5}{*}{ Tenencia } & $\begin{array}{l}\text { Propietario de vivienda y } \\
\text { terreno }\end{array}$ & 5 & 10 & \\
\cline { 2 - 5 } & $\begin{array}{l}\text { Inquilino (Alquiler con } \\
\text { contrato) }\end{array}$ & & 2,5 & \\
\cline { 2 - 5 } & $\begin{array}{l}\text { Resto de las condiciones } \\
\text { Inodoro con descarga y } \\
\text { desagüe a red cloacal }\end{array}$ & 95 & 87,5 & 100 \\
\cline { 2 - 5 } & $\begin{array}{l}\text { Inodoro con descarga y } \\
\text { desagüe a cámara séptica + } \\
\text { inodoro con desagüe a pozo } \\
\text { ciego }\end{array}$ & 95 & 42,5 & 89,7 \\
\cline { 2 - 5 } & $\begin{array}{l}\text { Inodoro sin descarga o sin } \\
\text { inodoro }\end{array}$ & 2,5 & 5 & 10,3 \\
\hline \multirow{3}{*}{ Servicio sanitario } & Usado solo por este hogar & 97,5 & 97,5 & 89,7 \\
\hline \multirow{3}{*}{ Inodoro } & Compartido por otro hogar & 2,5 & 2,5 & 10,3 \\
\hline \multirow{2}{*}{ NBI Hacinamiento } & Si (más de 3 por cuarto) & 12,5 & 27,5 & 48,3 \\
\cline { 2 - 5 } & No cumple esta condición & 87,5 & 72,5 & 51,7 \\
\hline
\end{tabular}

Fuente. Entrevistas semiestructuradas realizadas en el año 2011.

Sobre las condiciones laborales, variable directamente vinculada a los ingresos (sobre todo en ámbitos urbanos), entre los jefes/as de hogar ocupados/as prevalece la precariedad de las inserciones laborales tanto en el caso de asalariados como de cuentapropistas (Tabla 2). Predominan también las bajas calificaciones de las ocupaciones, característica que se traduce en bajos niveles salariales. Los asalariados se desempeñan principalmente, en el caso de los varones, en la construcción y, las mujeres, en el servicio doméstico. Un sector participa en planes de empleo, sin acceso a ningún tipo protección social, y en cooperativas de trabajo promovidas por el Estado en las que si bien tienen ciertos beneficios sociales (obra social, Aseguradoras de riesgo de trabajo) perciben ingresos mínimos. Los trabajadores cuentapropistas son principalmente vendedores ambulantes y cartoneros que tienen como lugar de trabajo la zona céntrica del aglomerado (del Castillo, 2012).

\footnotetext{
${ }^{15}$ Si bien la acción estatal desde el año 2004 estuvo orientada al mejoramiento de la vivienda existente, a través de la construcción de módulos habitacionales, ésta mejoró los aspectos materiales, pero no incidió significativamente en las condiciones de hacinamiento.
} 
TABLA 2

Barrios seleccionados del GSMT. Características del Empleo en los jefes/as de Hogar

\begin{tabular}{|c|c|c|c|c|}
\hline $\begin{array}{c}\text { Característica } \\
s \\
\text { del empleo } \\
\end{array}$ & Variables & $\begin{array}{c}\text { Villa } \\
\text { Muñecas Norte } \\
\end{array}$ & $\begin{array}{c}\text { Juan } \\
\text { Pablo II } \\
\end{array}$ & $\begin{array}{l}\text { Costanera } \\
\text { Norte }\end{array}$ \\
\hline \multirow{2}{*}{$\begin{array}{l}\text { Formalidad } \\
\text { laboral }\end{array}$} & $\mathrm{Si}$ & 37,0 & 27,6 & 0 \\
\hline & No & 63,0 & 72,4 & 100 \\
\hline \multirow{4}{*}{$\begin{array}{r}\text { Relación } \\
\text { ocupacional }\end{array}$} & Patrón & 0 & 3,4 & 0 \\
\hline & $\begin{array}{l}\text { Trabajador por cuenta } \\
\text { propia }\end{array}$ & 29,6 & 34,5 & 85 \\
\hline & $\begin{array}{l}\text { Asalariado } \\
\text { (obrero/empleado sector } \\
\text { público+ obrero/empleado } \\
\text { sector privado) }\end{array}$ & 70,4 & 62,1 & 15 \\
\hline & $\begin{array}{c}\text { Trabajador familiar } \\
\text { (con sueldo o sin sueldo) }\end{array}$ & 0 & 0 & 0 \\
\hline \multirow{5}{*}{$\begin{array}{r}\text { Categoría } \\
\text { ocupacional }\end{array}$} & Calificación técnica & 0 & 10,3 & 0 \\
\hline & Calificación operativa & 63,0 & 31,0 & 0 \\
\hline & Calificación profesional & 0 & 0 & 0 \\
\hline & No calificada & 37,0 & 55,2 & 100 \\
\hline & $\begin{array}{l}\text { Otros (información } \\
\text { insuficiente) + calificación } \\
\text { ignorada) }\end{array}$ & 0 & 0 & 0 \\
\hline
\end{tabular}

Fuente: Entrevistas semiestructuradas realizadas en el año 2011.

Las condiciones educativas de los jefes/as de hogar, variable que se relaciona con la escasa calificación de las ocupaciones e influye en las oportunidades de inserción laboral, son también críticas. Alrededor del 50\% no tiene instrucción o no terminó la escuela primaria (Tabla 3). En el caso del barrio Costanera Norte, dicha magnitud alcanza al 70\% de su población.

TABLA 3

Barrios seleccionados del GSMT. Niveles educativos del Jefe/a de Hogar

\begin{tabular}{|c|c|c|c|c|}
\hline Niveles educativos & Variables & $\begin{array}{c}\text { Villa } \\
\text { Muñecas } \\
\text { Norte }\end{array}$ & $\begin{array}{c}\text { Jua } \\
\text { n Pablo } \\
\text { II }\end{array}$ & $\begin{array}{r}\text { Costan } \\
\text { era Norte }\end{array}$ \\
\hline \multirow{9}{*}{$\begin{array}{l}\text { Mayor nivel educativo } \\
\text { del jefe de hogar }\end{array}$} & Universitario completo & 0 & 0 & 0 \\
\hline & $\begin{array}{l}\text { Universitario } \\
\text { incompleto }\end{array}$ & 0 & 0 & 0 \\
\hline & Terciario completo & 0 & 0 & 0 \\
\hline & Terciario incompleto & 2,5 & 0 & 0 \\
\hline & Secundario completo & 7,5 & 2,5 & 0 \\
\hline & Secundario incompleto & 0,0 & 7,5 & 0 \\
\hline & Primario completo & 45,0 & 50 & 24,1 \\
\hline & Primario incompleto & 22,5 & 27,5 & 62,1 \\
\hline & Sin instrucción & 22,5 & 12,5 & 13,8 \\
\hline
\end{tabular}

Fuente: Entrevistas semiestructuradas realizadas en el año 2011.

Al indagar específicamente sobre las relaciones entre la pobreza como contexto de la desnutrición infantil se observa en estos hogares que el estado nutricional de la población 
infantil (niños hasta 14 años) alcanza diferentes magnitudes en los barrios considerados ${ }^{16}$. En el caso del barrio Villa Muñecas Norte incluye al 9\% de la población infantil, en el Barrio Juan Pablo II al $4 \%$ y en Costanera Norte al 6\% según los Resúmenes de Ronda del año 2009. Todos estos niños se encontrarían en el primer grado o nivel de desnutrición.

El análisis de ciertas características de los hogares afectados por la desnutrición infantil teniendo a la pobreza crítica como condicionante estructural-, y de las acciones que despliegan frente al problema, a partir de las entrevistas realizadas, permite aproximarnos al conocimiento sobre los posibles determinantes inmediatos y mediatos.

Podemos señalar que -en general- se tratan familias con un promedio de cinco personas, en su mayoría con niños de corta edad. Se encuentran normalmente en el primer ciclo reproductivo, característica que dispone mayores requerimientos nutricionales por los graves efectos de una inadecuada alimentación en la niñez.

El 71\% de los/as jefes/as de hogar con presencia de niños desnutridos habían alcanzado un nivel educativo que no supera el nivel primario completo. El porcentaje restante solo curso hasta tercer grado. Parece, ante esta evidencia, ser sólidas las experiencias previas que destacan el impacto del menor capital educativo (sobre todo materno) en la mayor probabilidad de apariencia y desarrollo de desnutrición infantil ${ }^{17}$.

A nivel laboral se desempeñan, en todos los casos aquí analizados, en condiciones de precariedad y en actividades de baja calificación. En el 30\% de los hogares trabajan ambos cónyuges, en un 30\% declara que sólo trabaja el jefe de hogar y las mujeres -que se identifican como amas de casa- son beneficiarias del Programa Ellas Hacen. Dicho programa establece una contraprestación laboral a través del trabajo en cooperativas para el mejoramiento barrial, además de la conclusión de los niveles primario y secundario. La identificación como amas de casa puede deberse a las dificultades, desde las instituciones encargadas de su ejecución, para poner en práctica las cooperativas.

Por otro lado, la percepción de la Asignación Universal por Hijo permite disponer a los hogares de ingresos fijos al mes siendo éstos muy importante en la estructura de gastos familiares.

El promedio de gastos diarios en alimentación es de \$95. La realización de las compras se realiza, por lo general, en las despensas de los barrios. En algunos casos refieren compras en los supermercados, sobre todo en los hogares que reciben una percepción mensual o perciben los mencionados planes. En las despensas se recurre habitualmente al fiado, lo cual les permite asegurar al menos una comida diaria.

El $43 \%$ de estos hogares cocina una vez por día, y el porcentaje restante dos veces. El desayuno y la merienda son reservados para los niños. Los que se encuentran en edad escolar reciben una colación en la escuela consistente en yogurt, leche chocolatada o sándwich de queso. Los adultos recurren generalmente al mate. Aguirre (2004) ha puesto claramente en evidencia la diferenciada alimentación en los contextos de pobreza, siendo dominada por harinas y productos industrializados. La presencia del mate, como pudo observarse, no constituye una excepción.

La comida que preparan con mayor frecuencia es el guiso, seguido habitualmente de estofados y sopas. La preparación de otros menús que incorporan más carne (milanesas, carne asada) son eventuales y por lo general ocurren en la fecha de cobro de los programas o salarios. A fin de mes, cuando el dinero escasea, se suele afectar la cena, reemplazándola normalmente por alguna infusión caliente como el mate, fideos hervidos o "a lo que se puede preparar". En algunos casos - como estrategia de supervivencia- envían los niños a la casa de familiares para garantizar que no se suprima la alimentación.

Los niños con problemas nutricionales recurren regularmente a los comedores infantiles cuando éstos se encuentran disponibles en el barrio. En el caso de Costanera Norte, durante los

\footnotetext{
${ }^{16}$ Según UNICEF (2006) los niños que padecen esta patología, casi con seguridad, van a ver afectado su desarrollo físico e intelectual a corto, medio y largo plazo, hipotecando no sólo su futuro sino el de sus familias, comunidades y sociedad en general.

${ }^{17}$ Ver De Tejada Lagonell et al., (2005)
} 
últimos años, se produjo el cierre de distintas opciones institucionales que funcionaban en la zona.

Sobre el tratamiento y asistencia sanitaria que reciben los hogares que se encuentran afectados por la problemática, desde los CAPS se implementa un control mensual de peso y talla, atención médica y presencia de nutricionista con carácter mensual, como así también las visitas periódicas de los agentes sanitarios. Por cada niño afectado se entrega de manera mensual dos cajas de leche y una tarjeta de débito con un crédito $\$ 120$ que sólo habilita la compra de carnes y lácteos en determinados supermercados. Esta última prestación forma parte del Programa de Abordaje Integral de Nutrición (Tarjeta Cabal) dependiente de los Ministerios de Salud y de Desarrollo Social de la provincia.

Los entrevistados, en todos los casos analizados, expresaron dificultades para acceder a los alimentos deseados ya que no les alcanzan los ingresos. Como estrategia procuran cubrir algunos de los requerimientos alternando con lo que come el resto de la familia. En los casos analizados no refieren la intervención de otras instituciones.

En los niños afectados es frecuente la presencia de enfermedades bronco-respiratorias y diarreas. La primera línea de asistencia son los CAPS y cuando los cuadros se agravan recurren al Hospital de Niños de la provincia. Cabe destacar que las características habitacionales favorecen estos cuadros ya que en todos los casos las viviendas, como se mencionara, son precarias, y se encuentran en entornos con carencias en el acceso a los servicios básicos. No disponen de red cloacal, la recolección de residuos se realiza cada tres días y las calles son de tierra, características que a su vez inciden sobre la prevalencia de dichas enfermedades.

\section{CONCLUSIONES}

La desnutrición infantil es tal vez aquella manifestación más crítica y cruel de la pobreza, no sólo por las secuelas permanentes que deja sino porque asume -tal el enfoque metodológico aplicado- como forma extrema la muerte infantil. Constituye por lo tanto un núcleo duro de privación y vulnerabilidad que debiera ser prioritario en las políticas públicas.

Existen, no obstante, muchas barreras para su conocimiento y análisis dependiendo incluso de la escala que se utilice y las fuentes que se empleen. En nuestro estudio, una investigación de escala provincial con enfoque diacrónico y sincrónico, que articula métodos cuantitativos y cualitativos, difícilmente pueda haberse realizado sobre la base de encuestas y muestras poblacionales. En tal sentido implicó la formulación y desarrollo de herramientas metodológicas y conceptuales que permitan abordar el problema con cierta precisión. Sin embargo, esta formulación estuvo supeditada a las fuentes de información y sus características, por tal motivo debimos acudir a una faceta de la desnutrición infantil extrema, es decir la muerte en la niñez codificada como tal, permitiéndonos aproximarnos apenas a una parte -mínima- del problema en la provincia, y a partir de ello tomar noción (con alcance limitado) de la gravedad, magnitud, tendencias y alcances que presenta.

¿Cuáles son las principales manifestaciones de la desnutrición infantil en Tucumán? ¿Qué magnitudes presenta actualmente? ¿Cuáles fueron las tendencias dominantes? ¿Qué acciones desarrolla la población para afrontar el problema? ¿Cuál es la incidencia de las políticas sociales y sanitarias? Fueron estos los principales interrogantes que orientaron las distintas aproximaciones a las que abordamos en la investigación. El desarrollo metodológico para responder dichos interrogantes implicó la construcción de un indicador susceptible de acercarse con cierto grado de precisión a la problemática estudiada que tuvo a su vez su correlato en un modelo teórico conceptual. La Tasa de mortalidad en la niñez por desnutrición por causas directas y asociadas pretendió alcanzar tales requisitos. Esta tasa -que se convierte de alguna manera en un indicador extremo al considerar solo la mortalidad y no la morbilidad- incluyó no solo las muertes directas registradas y codificadas por desnutrición, sino también aquellas asociadas o contributivas del cuadro de desnutrición, entre las que figuran las diarreas, septicemias, neumonías, bronquiolitis, parasitismo, entre otras, la cuales, ante su aparición y desarrollo, ponen de manifiesto el grado de vulnerabilidad nutricional en el que se encuentran sometidas determinadas poblaciones y el sinergismo que las relaciona a la desnutrición. 
El cálculo y análisis de esta tasa, tanto en un enfoque diacrónico -que va desde 1994 hasta 2012-, como en un enfoque sincrónico y de distribución espacial permitió hallar resultados que confirman un proceso de estancamiento en su transición epidemiológica, con la reaparición de ciertas patologías controladas asociadas a la desnutrición, y la existencia de magnitudes muy altas en algunas de ellas. Estas características profundizan una brecha socioeconómica que consolida una fragmentación socio-territorial con profundas consecuencias en el bienestar de la población, que se expresan a su vez en el plano social, económico, político, cultural e incluso con alcances éticos y morales.

Se ha observado que a pesar de grandes avances en materia de reducción de pobreza y mejora de las condiciones de vida en la población infantil en los primeros años del siglo XXI si se los compara con la década del '90- se destacan las magnitudes increíbles que alcanzan las cifras de desnutrición infantil en Argentina en general y en Tucumán en particular. Las fuentes utilizadas permitieron distinguir a 110 niños fallecidos directamente por desnutrición en la provincia, y a otros 625 por patologías relacionadas o asociadas al cuadro nutricional, evidenciando la existencia y consolidación de un flagelo que, dado el grado de conocimientos existentes, debería haber sido erradicado de la provincia.

Los estudios de caso aplicados en hogares pobres con la existencia de niños que padecen desnutrición crónica evidencian la íntima relación de la pobreza con la desnutrición infantil, en tanto condición estructural que no sólo se vincula con la insuficiencia de ingresos sino con la precariedad habitacional y las condiciones edilicias. Estos constituyen factores de vulnerabilidad que, en la mayoría de los casos, se imponen sobre las acciones que desarrollan las familias para enfrentar el problema. Las respuestas estatales que se han puesto en marcha ante estos problemas tienen un carácter asistencial dirigido sólo a atenuar los efectos del deterioro social y sanitario sin asegurar umbrales de satisfacción adecuados. Desconocen, por otro lado, los aspectos estructurales de la condición detectada. Finalmente, enfatizan en grado nulo sobre proyectos de prevención del problema.

Lejos de ser una cuestión del pasado, la desnutrición en la niñez constituye uno de los problemas de mayor relevancia en la actualidad, identificando a partir de su concentración, por lo menos, diferentes territorios con condiciones de vida disímiles que conviven en el marco de una misma nación y una misma provincia. Las evidencias halladas muestran que la desnutrición, a pesar de haber descendido, presenta magnitudes que la posicionan como uno de los más importantes problemas provinciales de salud pública, influyendo en gran medida en las altas tasas de morbilidad y mortalidad infantil, así como en la prevalencia de ciertas enfermedades crónicas, difíciles de cuantificar. Asimismo, el costo económico de la enfermedad es muy alto también (gastos hospitalarios, productividad, gastos en educación, menor poder adquisitivo, etc.), y el daño cerebral irreversible que genera, también complejo de cuantificar, aunque con profundas connotaciones éticas y morales.

\section{BIBLIOGRAFÍA}

AGUIRRE P. 2000 (2000): Aspectos socio antropológicos de la obesidad en la pobreza. "La obesidad en la pobreza: un nuevo reto para la salud pública". En Peña M. y Bacallao J. (Ed). Washington, D.C.: Organización Panamericana de la Salud, pp. 13-25.

AGUIRRE, P. (2004): Ricos flacos y gordos pobres: la alimentación en crisis. Capital intelectual, Buenos Aires.

AGUIRRE, P. (2005): Estrategias de consumo: qué comen los argentinos que comen. Ciepp. Miño y Dávila, Buenos Aires, Primera Edición julio.

ALAZRAQUI, M.; MOTA, E. y SPINELLI, H. (2005): Sistemas de información en salud: proceso dialéctico DICCA. Trabajo presentado en $9^{\circ}$ congreso mundial de información en salud y bibliotecas. El Salvador.

BALDRICH, Alberto. (1944): La desnutrición infantil es un serio problema. "Revista de Economía Argentina", № 308, año 26, Tomo 43, pp. 41-42. 
BERTARINI, J. (2011): Evaluación del Estado Nutricional materno-infantil y Patrones de consumo maternos. Universidad de Fasta., Facultad de Ciencias Médicas. Tesis de Licenciatura en Nutrición. http://redi.ufasta.edu.ar:8080/xmlui/handle/123456789/304

BOLSI, A. (2007): El mito de la opulencia argentina: territorio y pobreza en el Norte Grande. Actas latinoamericanas de Varsovia, (30), pp. 189-206.

BOLSI, A., LONGHI, F., y PAOLASSO, P. (2009): Pobreza y mortalidad infantil en el norte grande argentino. Un aporte para la formulación de políticas públicas. "Cuadernos Geográficos", 45, 231-261.

BOLSI, A.; MADARIAGA, H.; MEICHTRY, N.; y PAOLASSO, P. (2009). Capítulo I: Objetivos y Métodos. "Geografía de la pobreza en el Norte Grande Argentino". En Bolsi A. y Paolasso, P. (Comp.). Tucumán: UNT-CONICET, pp. 17-28.

BOLSI, A. y MIGNONE, M. (2009): La pobreza en los aglomerados urbanos del Norte Grande Argentino. "Geografía de la pobreza en el Norte Grande Argentino". En Bolsi A. y Paolasso, P. (Comp.). Tucumán: UNT-CONICET, pp. 237-246.

BOLZÁN, A. y MERCER, R. (2009): Seguridad alimentaria y retardo crónico del crecimiento en niños pobres del norte argentino. "Arch. Argent. Pediatr", vol.107, n.3, pp. 221-228.

BOLZÁN, A. y MERCER, R. (2009): Seguridad alimentaria y retardo crónico del crecimiento en niños pobres del norte argentino. “Arch. Argent. Pediatr.”,107(3), pp. 221-228

BRITOS, S. (2003): Crisis 2001-2002: pobreza, precios y alimentos. Centro de Estudios sobre Nutrición Infantil (CESNI), Buenos Aires.

BRONFMAN, M. (2001): Como se vive se muere. Centro Regional de Investigaciones Multidisciplinarias. CRIM.

CALVO, E.; AGUIRRE, P. y coordinadores provinciales (2005): Crisis de la seguridad alimentaria en la Argentina y estado nutricional en una población vulnerable. "Arch. Argent. Pediatr", 103, pp. 71-90.

CALVO, E. y AGUIRRE, P. (2005). Crisis de la seguridad alimentaria en la Argentina y estado nutricional en una población vulnerable. "Arch. Argent. Pediatr.", 103, pp. 77-90.

CARMUEGA, E., y O'DONNELL, A. (1998): Hoy y mañana. Salud y calidad de vida de la niñez argentina. Argentina.

CARMUEGA, E. y DURÁN, P. (2000): Valoración del estado nutricional en niños y adolescentes. "Boletín CESNI", junio, Centro de Estudios sobre Nutrición Infantil, Buenos Aires.

CHACKIEL, J. (1987): La investigación sobre causas de muerte en América Latina. "Notas de Población", 44, pp. 9-30.

DE TEJADA LAGONELl, M., DE TINEO, A. G., MÁRQUEZ, Y., \& BASTARDO, L. (2005): Escolaridad materna y desnutrición del hijo o hija. Centro Clínico Nutricional Menca de Leoni. “Anales Venezolanos de Nutrición”, 18 (2), pp. 162-168.

DEL CASTILlO, A. (2012): Pobreza y "cartoneo" en un barrio periférico del Gran San Miguel de Tucumán. "Revista cuadernos FHYCS-UNJU", 41.

DEMONTE, F. (2011): La construcción de la malnutrición infantil en la prensa escrita argentina durante la crisis de 2001. "Salud Colectiva", 7 (1), pp. 53-71, enero-abril.

DÍAZ MUÑOZ, A. (1995): Limitaciones de las estadísticas vitales como fuente de información para el estudio de la mortalidad infantil. Trabajo presentado en III Jornadas Argentinas de Estudios de Población, Buenos Aires.

DURÁN, P., MANGIALAVORI, G., BIGLIERI, A., KOGAN, L., y ABEYÁ GILARDON, E. (2009): Estudio descriptivo de la situación nutricional en niños de 6-72 meses de la República Argentina. Resultados de la Encuesta Nacional de Nutrición y Salud (ENNyS). “Arch Argent Pediatr”, 107(5), pp. 397-404.

FAO (2014): Panorama de la Seguridad Alimentaria y Nutricional en América Latina y el Caribe. Hambre en América Latina y el Caribe: acercándose a los Objetivos del Milenio.2013. www.fao.org/publications

FAO. (2001): Perfiles nutricionales por países: Argentina. Organización de las Naciones Unidas para la agricultura y la alimentación.

GÓMEZ, F. (2003): Desnutrición. "Salud Pública de México", vol. 45, No 4 (Supl.), pp. 576582. 
GÓMEZ, A.; MARIO, S.; y OLMOS, F. (2003): Índice de Privación Material de los Hogares (IPMH). Desarrollo y aplicación con datos del Censo Nacional de Población y Viviendas 2001. VII Jornadas Argentinas de Estudios de Población (AEPA), Universidad Nacional de Tucumán, Tafí del Valle, Tomo II: 1001-1017.

HERKOVITS, D. (2007): La construcción de la malnutrición Infantil: Una Etnografía sobre las condiciones y posibilidades que contribuyen a su producción y reproducción en hogares pobres de la Ciudad de Buenos Aires (Doctoral dissertation, CEDES).

HERKOVITS, D. (2012): Las fronteras de la medicalización: tensiones en torno a la identificación y valoración de la desnutrición infantil en un centro de atención primaria de la ciudad de Buenos Aires. "Ciênc. saúde coletiva", 17(9), pp. 2543-2551.

HOMMES, R. y SOTO, C. (1999): Determinantes socioeconómicos de la mortalidad infantil en países en desarrollo: un estudio de corte transversal. "Pobreza y desigualdad en América Latina” En Cárdenas M. y Lustig, N. (comp.). Bogotá: Tercer Mundo Editores, pp.187-210.

JASPERS - FAIJER, D. y ORELLANA, H. (1994): Evaluación del uso de estadísticas vitales para estudios de causas de muerte en América Latina. "Notas de Población", 60, 47-77.

KLIKSBERG, B. (2005): América Latina: La región más desigual de todas. "Revista de Ciencias Sociales", 11(3), pp. 411-521.

LONGHI, F. (2009): Miseria, mortalidad infantil y perfil epidemiológico en el Norte Grande Argentino. "Medio siglo de padecimientos en grupos vulnerables del interior argentino, 1989-2003". En Drovetta, R. y Rodríguez, M.L.(Comps.). Centro de Estudios Avanzados/Universidad Nacional de Córdoba.

LONGHI, F. (2012): Sistemas de Información Geográfica y desnutrición infantil en el Norte Grande Argentino. "Revista Latinoamericana de Población", pp. 77 - 101.

LONGHI, F. (2014). Desnutrición y Muerte en la Niñez argentina en los Albores del Siglo XXI: Un Análisis Espacial. "Journal of Latin American Geography", 13 (2), pp. 41-65.

MARTÍNEZ, R. y FERNÁNDEZ, A. (2006): Modelo de análisis del impacto social y económico de la desnutrición infantil en América Latina. CEPAL.

MEDWID, B. (2008): Mitos y realidades de la poberza y el Mercosur. El caso de la industria azucarera en Tucumán. "La economía política de la pobreza". En Cimadamore, A. CLACSO, Buenos Aires.

MERCER, R. (2013): Salud y pobreza en la Argentina Dime cómo ha sido tu cuna y te diré cómo serás... "La Dignidad de los Nadies. Voces en el Fénix", $\mathrm{n}^{\circ} 22$. Disponible en: http://www.vocesenelfenix.com/content/salud-y-pobreza-en-la-argentina-dime-c\% C3\%B3mo-ha-sido-tu-cuna-y-te-dir\%C3\%A9-c\%C3\%B3mo-ser\%C3\%A1s \%E2\%80\% A6A.

MORENO, M. (1995): La pobreza: una medición en busca de su contenido conceptual. Trabajo presentado en III Jornadas Argentinas de Estudios de Población, Santa Rosa.

O’DONNELL, A. y PORTO, A. (2007) : Las carencias alimentarias en el país. Su impacto sobre el desarrollo infantil. "Pobreza y desarrollo infantil. Una contribución multidisciplinaría". En Colombo, J. (Ed.). Paidos, pp.141-155.

ORTIZ-ANDRELLUCCHI, A., QUINTANA, L. P., BEÑACAR, A. A., BARROS, F. M., \& SERR, L. (2006): Desnutrición infantil, salud y pobreza: intervención desde un programa integral. "Nutrición Hospitalaria", 21(n04).

OYHENART E., TORRES MF, QUINTERO FA, LUIS MA, CESANI MF, ZUCCHI M, et al. (2007): Estado nutricional y composición corporal de niños pobres residentes en barrios periféricos de La Plata, Argentina. "Rev. Panam Salud Publica", 22(3), pp.194-201.

OYHENART, E., DAHINTEN, L., ALBA, J., ALFARO GÓMEZ, E., BEJARANO, I., CABRERA, G. \& LUIS, M. (2008): Estado nutricional infanto juvenil en seis provincias de Argentina: variación regional. "Revista Argentina de Antropología Biológica", 10.

PENIÉ, J. B. (2000): Desnutrición e infecciones respiratorias. "Acta Médica", (9), pp. 15-21.

RODRÍGUEZ MARQUINA, P. [1899] (2012): La mortalidad infantil en Tucumán. "La mortalidad infantil en Tucumán”. En Longhi, F. (ed.). Imago Mundi, Buenos Aires, pp. 1108. 
TORRADO, Susana (1986): Salud - enfermedad en el primer año de vida, Rosario (19811982). Centro de Estudios Urbanos y Regionales, Buenos Aires.

UNICEF (2011): La desnutrición infantil. Causas, consecuencias y estrategias para su prevención y tratamiento. España www.unicef.es

UNICEF (2006): Desnutrición infantil en América Latina y el Caribe. "Desafíos", no 2. Disponible en: http://www.unicef.org/lac/Desafiosnutricion(13).pdf

WANDEN-BERGUE, C.; CAMILO, M.E.; CULEBRAS, J. y RED DE MALNUTRICION EN IBEROAMERICA del Programa de Ciencia y Tecnología Para el Desarrollo (Red MelCyted) (2010): Conceptos y definiciones de la desnutrición iberoamericana. "Nutr. Hosp.”, vol.25, suppl.3. 